\title{
DEVELOPMENT AND TESTING OF THE PNEUMATIC AND OUTPUT SYSTEM OF THE FANUC SPIDER ROBOT
}

\author{
Gyula KORSOVECZKI, ${ }^{1}$ Géza HUSI, ${ }^{2}$ Timotei István ERDEI ${ }^{3}$ \\ University of Debrecen, Engineering Faculty, Mechatronics Department, Debrecen, Hungary \\ ${ }^{1}$ korsoveczki.gyula@gmail.com \\ ${ }^{2}$ husigeza@eng.unideb.hu \\ 3 timoteierdei@eng.unideb.hu
}

\begin{abstract}
The aims of this paper are the development and testing of the pneumatic and output system of the FANUC Spider selecting robot that can be found at the Mechatronics Department, Engineering Faculty of the University of Debrecen. As a result the robot was shown to be capable of several working procedures with the use of the pneumatic vacuum gripper and the use of digital outputs.
\end{abstract}

Keywords: FANUC, Spider robot, delta-parallel tripod, pneumatics, 3D printing.

\section{Introduction}

In the Cyber-Physical and Intelligent Robot Systems Laboratory of the Building Mecha-tronics Research Centre of the University of Debrecen we focus on developing new tech-nologies for the industry. Recently we have enlarged the workplace of the KUKA KR5 in-dustrial robot which can be found at the Mechatronics Department by building a new robot cell around that [1]. Through these workstations we have the oppor-tunity for the real time and aligned application of the robot units. This is very important in industry 4.0. [2], [3], [4]. The purpose of the project was to enlarge the working opportunities of a modern industrial robot. To achieve this we chose to develop the pneumatic and output systems.

\section{General information about the robot}

The subject of the project is a delta-parallel, hybrid-kinematic designed robot that is produced by the Japanese FANUC Corporation. The robot has 6 controlled axes and the number of the degrees of freedom is 6 . The maximal reach of the robot is $280 \mathrm{~mm}$ and its maximal velocity is $4000 \mathrm{~mm} / \mathrm{s}$. Moreover the repeatability is $+/-0.02 \mathrm{~mm}$, the maximal load capacity at rest is $0.5 \mathrm{~kg}$ and the complete mechanical weight is $23 \mathrm{~kg}$. In the case of the voltage supply, the robot requires $50 / 60 \mathrm{~Hz}$, 200-230 V single phase voltage. The scope of the application is electronics, food products industry, manufacture of medical instruments, optic and medical industry and precision mechanics [5].

The robot is controlled by a FANUC R-30iB Mate Open Air type controller. It is compact designed, not based on the Windows operating system, and without an application framework [6].

The iPendant Touch is the FANUC's own hand controller. By this we can program the robot using the ON_LINE indirect method [7]. Figure 1. show the robot and its main parts:

\section{The design of the switching circuit}

The physical location of the outputs is beneath the surface of the robot. They are contained by
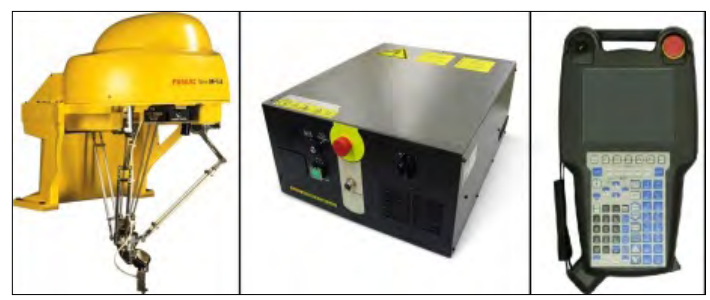

Figure 1. The robot and its main parts [5] [6] [7] 
a small black platform. The users can reach the outputs through this.

The function of the switching circuit is to switch the correct relay for the effort of $24 \mathrm{~V}$ that arrives from the corresponding output of the robot. This relay actuates the solenoid valve.

The switching circuit includes 2 integrated circuits that have 16 pins per IC. The $1^{\text {st }}, 3^{\text {rd }}, 5^{\text {th }}$ and $7^{\text {th }}$ pins of the first integrated circuit, and the 1 st and $3^{\text {rd }}$ pins of the second integrated circuit are connected one by one to the RO1, RO2, RO3, RO4, RO5 and RO6 outputs of the robot by the use of a $2.5 \mathrm{k} \Omega$ resistor per output. The $2^{\text {nd }}, 4^{\text {th }}, 6^{\text {th }}$ and 8th pins of the first integrated circuit and the $2^{\text {nd }}$ and $4^{\text {th }}$ pins of the second integrated circuit are connected to the FANUC GND output. The $16^{\text {th }}$, $14^{\text {th }}, 12^{\text {th }}$ and $10^{\text {th }}$ pins of the first device and the $16^{\text {th }}, 14^{\text {th }}$ pins of the second device are connected to the $24 \mathrm{~V}$ DC voltage supply. The $15^{\text {th }}, 13^{\text {th }}, 11^{\text {th }}$ and $9^{\text {th }}$ pins of the first IC and the $15^{\text {th }}, 13^{\text {th }}$ pins of the second IC are connected to the bases of the Darlingtons by the use of $4.7 \mathrm{k} \Omega$ resistor per Darlington. A power supply produces 24V DC and $3 \mathrm{~A}$ direct current. The collector pins of the Darlingtons are connected to the $24 \mathrm{~V}$ DC voltage and the emitter pins are connected to the GND of the voltage power supply. Since the Darlingtons and the outputs are connected to different GNDs, the galvanic isolation is achieved. This protects the robot in the case of malfunction of the switching circuit. Moreover the switching circuit contains 1 safety diode per Darlington which are connected to the $24 \mathrm{~V}$ DC voltage and the collector legs of the Darlingtons parallel to the relays. They protect the relay against reverse current. The signals that arrive from the output of the robot are collected by an RS232 connector. The pinout is defined such that the pins from 1 to 6 are connected to the robot output in order from RO1 to RO6. Moreover one of the GND outputs of the robot is also connected to pin 9. The input side of the TIL199 integrated circuits that are used for collecting the signals consist of 4 infrared light emitting diodes. Their forward voltage is $1.2 \mathrm{~V}$ [8]. Since the signal rate of the FANUC robot is $24 \mathrm{~V} \mathrm{DC}$, there is needed to use $2,5 \mathrm{k} \Omega$ resistors to reduce this value to the forward voltage. The functions of the 4,7 $\mathrm{k} \Omega$ resistors are the same. As the TIP120G type Darlingtons are actuated by 4,4 mA strength current, there is a requirement to reduce the current strength that arrives from the integrated circuit. The circuit diagram of the switching circuit is in Figure 2.
The working of the circuit is simple. A $24 \mathrm{~V} \mathrm{DC}$ signal comes from the output of the robot. This signal arrives at the RS232 connector and after that is reduced to the necessary voltage of the infrared LED by the $2.5 \mathrm{k} \Omega$ resistor. This infrared LED activates the photo Darlington that is placed on the output side of the inte-grated circuit. In this case the photo Darlington is conductor. The transferred current is reduced by the $4.7 \mathrm{k} \Omega$ resistor to the strength of the base current of the Darlington, which is $4.4 \mathrm{~mA}$. As result the previously opened contact of the relay turns into normally closed to activate the solenoid valve. When the output signal of the robot disappears, the switching circuit releases the path of the current to deactivate the relay and the solenoid valve.

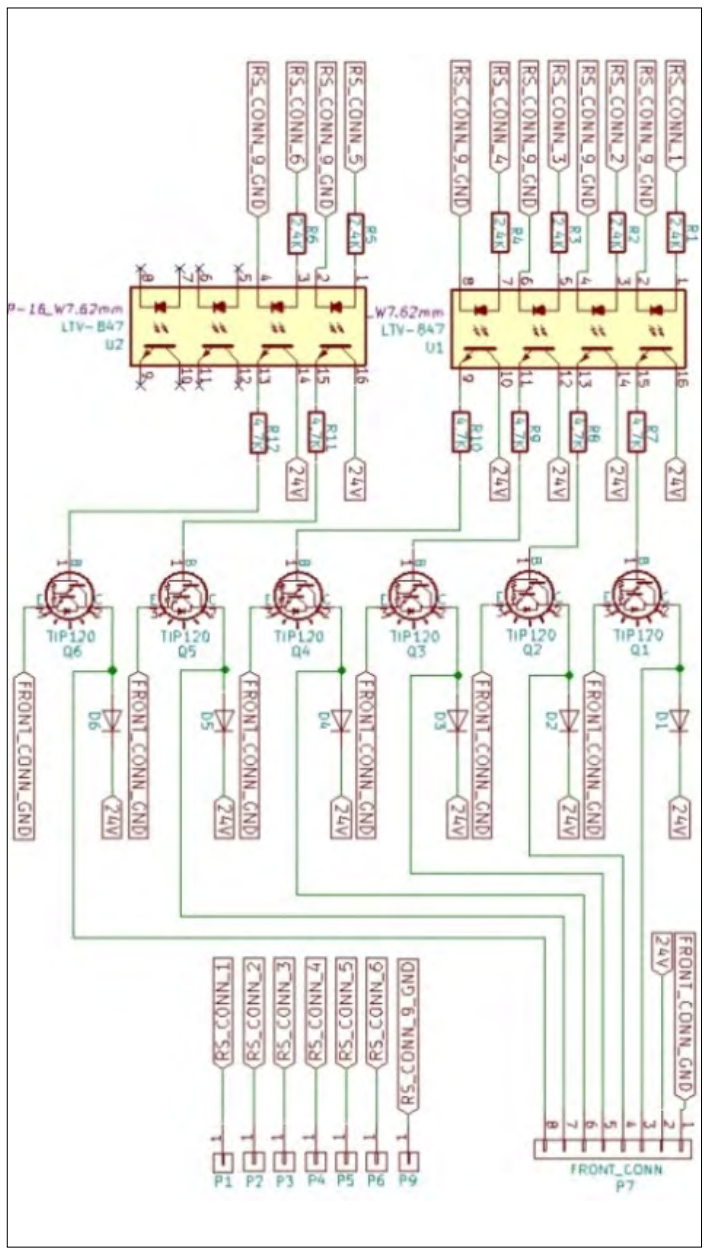

Figure 2. The circuit design of the circuit 


\section{The units of the electro pneumatic system}

The applied gripper device is a pneumatic vacuum gripper. Its full length is $10 \mathrm{~mm}$ and the weight is $5.5 \mathrm{~g}$. It is made of stainless steel. It has screw connection possibility, and its sucker type is interchangeable. The applied sucker is harmonic designed therefore it has a special elastic effort. The length of the sucker is $12 \mathrm{~mm}$, inside diameter is $5 \mathrm{~mm}$. It is suitable in the case of surfaces that are not completely horizontal or that have small surface-raggedness [9].

The ejector is a $\mathrm{ZH}$ type pneumatic vacuum ejector, produced by SMC. It has maximal $-90 \mathrm{kPa}$ vacuum pressure. The length of the device is $58.5 \mathrm{~mm}$, its weight is $88.4 \mathrm{~g}$ and it has 3 pneumatic fittings. The inside diameter of the fitting is $6 \mathrm{~mm}$ and it is cutting-ring designed [10]. Since the exhaust air is very noisy in all cases, the ejector possesses a silencer as well. This silencer is an ANA1 type, SMC produced device that keeps the level of the noise under $40 \mathrm{~dB}$ [11].

The used valve is a VZ51 type, SMC produced, monostable, piloted, 3/2 way, spring-returned, normally closed electro pneumatic solenoid valve. The required voltage level is $24 \mathrm{~V} \mathrm{DC}$, and the working air pressure domain is between $0.15 \mathrm{MPa}$ and $0.7 \mathrm{MPa}$. The solenoid valve possesses 3 fittings. There is a work fitting that is marked 2 (A), there is an air supply fitting that is marked $1(\mathrm{P})$ and there is an exhaust fitting that is marked 3 (R). It has 2 standings. [12].

The input air is regulated by an AR10-M5-Z type, SMC produced air regulator with a G27-10-R1 type, SMC produced indicator. The regulator possesses an indicator as well, which has a 0-10 MPa air pressure domain indicator table. It gives information about the regulated strength of the air pressure. The regulator can be fixed by the use of a plastic screw-ring into an open-end hole [13].

The applied pneumatic units can be seen in the Figure 3.

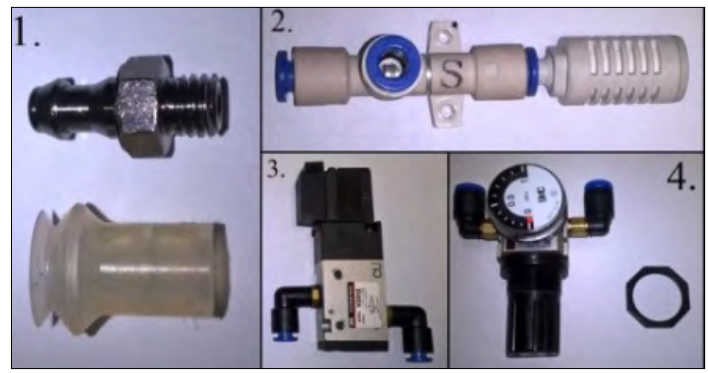

Figure 3. The applied units

\section{The 3D printed gripper-stabilizer}

For the effective working of the pneumatic vacuum gripper, a stabilizer is needed in which the gripper and the pneumatic tube is placed. In the case of the design, an important viewpoint was the length of the stabilizer. The working of the vacuum gripper requires vertical position, therefore the length of the stabilizer weighs with the useable workspace. The work sphere of the robot is spherical, the higher $\mathrm{Z}$ position results in less sideward mo-tion. The path of the pneumatic tube is another important viewpoint, because it needs to enter the inside of the stabilizer. This means that the path of the tube is radial. Therefore it has to correspond to the material of the pneumatic tube and also to the typical bending radius, which is $20 \mathrm{~mm}$. It was designed in Solid Edge design software and was produced by the use of 3D printing technology.

\section{Electric and pneumatic connections}

A fix platform is created inside the robot to fix an RS232 connector that collects by wires all of the output pins of the robot. The com-munication between this RS232 connector and the box of the switching circuit is solved by UTP cable.

Relays are connected to the switching circuit. The applied devices are 55.34.9.024.0040 type small industrial relays, produced by Finder for ordinary purposes. To fix them and to collect the signals 94.74 type relay sockets are used, which are compatible with the standard $35 \mathrm{~mm}$ width DIN rail. The box of the switching circuit and the power supply are also DIN rail compatible. The connections can be seen in Figure 4 .

The signal arrives from the output of the ro-bot. In case of the gripper we used the RO1. When the robot gives the $24 \mathrm{~V}$ DC signal level, the switching circuit actuates the right relay that is actually the K1. The relay actuates the solenoid valve and a vacuum is created by the ejector. As long as the

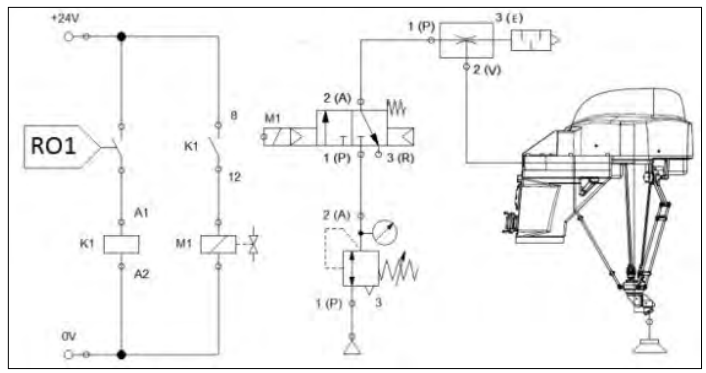

Figure 4. The principle of functioning 


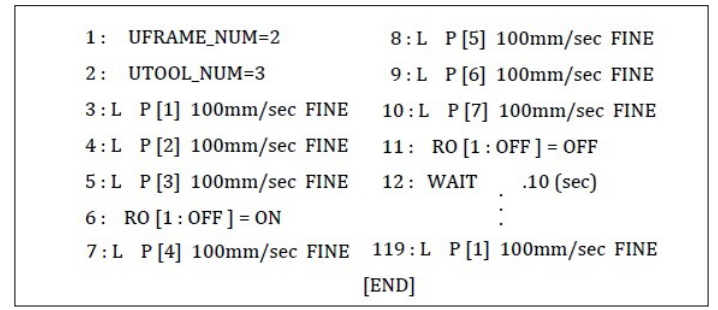

Figure 5. A part of the test program code

$24 \mathrm{~V}$ signal level arrives from the output of the robot, there is a vacuum in the gripper. In the case of the termination of the signal, the relay releases the connection and the vacuum terminates too.

A metal platform is created to place the electro pneumatic units. Moreover a work desk is created that is adjustable in directions parallel to $\mathrm{X}, \mathrm{Y}$ and $\mathrm{Z}$ directions of the World coordinate-system.

\section{The test program}

The final step was the testing and demon-strating of the accomplished developments by the use of a test program. The test program utilises a „pick and place” process. In this case objects are moved with different shape, weight and surface. The main part of the program code can be seen in the Figure 5.

\section{Conclusions}

During this project we developed the electro pneumatic and output system of the presented robot. As a result the robot was capable of using a vacuum gripper and actuators which can be controlled by digital signals. Thanks to these, the efficiency of the robot improved significantly. Further development possibilities could be the creation of a robot cell that includes a conveyor line, connection of actuators and programmable logical controllers and the picture-recognizing ability of the camera system.

\section{References}

[1] Erdei T. I., Molnár Zs., Obinna N. C., Husi G.: Cyber physical systems in mechatronic research centre. MATEC Web Conference, 126. (2017). https://doi.org/10.1051/matecconf/201712601006

[2] Erdei T. I., Molnár Zs., Husi G.: Robot visual and virtual control technology in industrial environment. WoS (Web of Science) publication, International Symposium on Small-Scale Intelligent Manufacturing Systems (SIMS), Narvik, NORWAY- IEEE, Jun 21-24, 2016.

https://doi.org/10.1109/SIMS.2016.7802902
[3] Erdei T. I., Molnár Zs., Obinna N. C., Husi G.: A Novel Design of an Augmented Reality Based Navigation System \& its Industrial Applications. 15th IMEKO TC10 - Technical Diagnostics in Cyber-Physical Era Budapest, Hungary, 6 - 7 June, 2017 - Organised by: MTA SZTAKI - Hungarian Academy of Sciences - Institute for Computer Science and Control.

[4] Obinna N. C., Erdei T. I., Molnár Zs., Husi G.: LabVIEW Motion Planning and Tracking of an Industrial Robotic Manipulator (KUKA KR5 arc): Design, Modelling, and Simulating the Robot's Controller Unit. In: A XXII. Fiatal müszakiak tudományos ülésszak előadásai. Proceedings of the $22^{\text {th }}$ international scientific conference of youngth engineers, Kolozsvár/Cluj, Románia, Müszaki Tudományos Közlemények 7. (2017). https://eda.eme.ro/handle/10598/29838

[5] FANUC Hungary Kft., $M-1$ iA $0.5 A$.

http://www.fanuc.eu/hu/hu/robotok/robotsz\%c5\%b1r\%c5\%91-lap/m1-sorozat/m-1ia05a. [accessed on: 23.02.2019.].

[6] FANUC America Corporation, R-30iA Mate controller. [accessed on: 23.02.2019.]

http://www.msamc.org/aimss/documentation/pdf/manuals/lr_mate_manuals/R30iA\%20 Mate\%20Controller.pdf

[7] FANUC Hungary Kft., FANUC iPendant Touch. http://www.fanuc.eu/hu/hu/robotok/tartoz\%c3\%a9kok/r-30ib-vez\%c3\%a9rl\%c5\%91/ipendant-touch. [accessed on: 23.02.2019.].

[8] Alldatasheet, TIL199. [accessed on: 23.02.2019.] https://pdf1.alldatasheet.com/datasheet-pdf/ view/85195/ETC/TIL199.html

[9] Mátyás A.: Vákuum megfogó és ejektor,” Vákuumos megfogó- és emelőberendezések, 22.10.2005.

[10] SMC Pneumatics, Vacuum Equipment. https://www.smcpneumatics.com/pdfs/ZH.pdf [accessed on: 23.02.2019.].

[11] SMC Pneumatics, ANA1 Silencer. https://content2.smcetech.com/pdf/ana1.pdf [accessed on: 23.02.2019.].

[12] SMC Pneumatics, 3 port Solenoid Valve, https://content.smcetech.com/pdf/VZ500.pdf [accessed on: 23.02.2019.].

[13] SMC Pneumatics, Pressure Gauge for General Purpose. accessed on: 23.02.2019.]. https://datasheet.octopart.com/G27-10-R1-SMCdatasheet-32029199.pdf. 